\title{
La Neorruralidad desde un Enfoque Antroposociocomunicacional
}

MHCJ n 6 | Año 2015

Artículo no 8 (69)

Páginas 195 a 217

mhcj.es
D ra. Luciana Geraldine Trimano| lucianatrimano@ conicet.gov.ar Centro de Investigaciones y Estudios sobre Cultura y Sociedad (CIECS) y Universidad Nacional de Córdoba (UNC)
Palabras clave

Neorruralidad; identidad; comunicación; configuración cultural.

Sumario

1. Introducción.

2. Sobre el pueblo y su configuración. Datos contextuales.

3. Cuestiones de método: un estudio de caso.

4. Una mirada antroposociocomunicacional: transdisciplina, teoría y enfoque metodológico. 4.1. Comunicación, producción de fronteras y configuraciones. 4.2. "Fronteras simbólicas", "fronteras de las identificaciones". 4.3. La comunicación: el espacio de lo común y "el espacio público muerto".

5. Reflexiones finales.

6. Referencias bibliográficas.

7. Notas.

\section{Resumen}

El presente artículo tiene como propósito desarrollar algunos aspectos teóricos y metodológicos acerca del fenómeno de la "neorruralidad". Esta tendencia de reestructuración poblacional supone analizar una alternativa de vida crítica con el modelo urbano y nuevas perspectivas sobre la ruralidad. La revalorización de los espacios rurales y la desvalorización residencial de los espacios urbanos se convierten, así, en una característica de este tiempo contemporáneo. Dicha temática ha sido escasamente problematizada en el ámbito de las ciencias sociales en general y de los estudios sobre comunicación, migraciones y movilidades en particular. A partir de la perspectiva etnográfica de los estudios de caso en una localidad rural, el fin es nutrir de información y sugerencias a otras búsquedas del campo de la comunicación y la cultura.

\section{Forma de citar este artículo en las bibliografías}

Dra. Luciana G eraldine Trimano (2015): "La Neorruralidad desde un Enfoque Antroposociocomunicacional", en Miguel Hernández Communication Journal, no66, páginas 195 a 217. Universidad Miguel Hernández, UMH (ElcheAlicante). Recuperado el _- de de 20 de: [ink del artículo en mhjournal.org] 


\section{Neo-rurality from a Socio-Anthropological and Communicational Approach}

M HC) nㅇ 6 | Year 2015

Paper no 8 (69)

Pages 195 to 217

mhcj.es
Dra. Luciana Geraldine Trimano| lucianatrimano@ conicet.gov.ar Centro de Investigaciones y Estudios sobre Cultura y Sociedad (CIECS) y Universidad Nacional de Córdoba (UNC)
Keywords

New Rurality; identity; communication; cultural configuration.

\section{Sumary}

1.Introduction.

2. The town and its configuration. Contextual data.

3. Questions of method: a case study.

4. Antroposociocomunicacional look: transdisciplinary, theory and methodological approach. 4.1.

Communication, production of borders and configurations. 4.2. "Symbolic borders",

"borders identifications." 4.3.

Communication: the common space and

"dead public space."

5. Final thoughts.

5. Bibliography.

5. Notes.

\section{Abstract}

This article is aimed at developing certain theoretical and methodological aspects on the "neo-rurality" phenomena. The tendency on population restructuration entails the analysis of an alternative of critical living under the urban model, and new perspectives on rurality. The revalorization of rural spaces and the devaluation of the residential aspect of urban spaces turn, this way, in a facet of this contemporary phenomenon. This issue has barely been problematized in the sphere of Social Sciences, in general, and in research on communication, migrations and mobility in particular. Based on an analysis of the case in a rural settlement, we aim to nurture and expand information and suggestions to trigger further quests on communications and culture fields.

\section{How to cite this paper in bibliographies}

Dra. Luciana Geraldine Trimano (2015): "La Neorruralidad desde un Enfoque Antroposociocomunicacional”, en Miguel Hernández Communication Journal, no6, páginas 195 a 217. Universidad Miguel Hernández, UMH (Elche-Alicante). Recuperado el _- de de 20 _- de: [link del artículo en mhjournal.org] 


\section{Introducción}

Durante mucho tiempo la comunicación fue concebida como el único objeto de investigación por el mundo académico. No conformes con este abordaje reduccionista, nos interpela otra propuesta, según la cual, entendemos a la comunicación como el lugar desde el que se mira determinado fenómeno social. Tratamos de pensarla más allá de los medios y los mensajes, para introducirla en el ámbito de las tramas culturales.

En el presente artículo desarrollamos aspectos teóricos y metodológicos para la interpretación de un fenómeno de corte emergente, ruptura, cambio e innovación como lo es la migración de la ciudad al campo o "neorruralidad", desde un enfoque antroposociocomnicaional (Trimano, 2014). Nuestro punto de partida es el análisis de caso en una localidad rural -Las Calles, ubicada en el Valle de Traslasierra, al oeste de la provincia de Córdoba, Argentina- impactada por la migración urbana, donde observamos conflictos e intercambios entre pobladores autóctonos e inmigrantes. Cabe destacar que esta temática ha sido escasamente problematizada en el ámbito de las ciencias sociales en general y de los estudios sobre comunicación, migraciones y movilidades en particular.

Para dar luz a la construcción de nuestro objeto de estudio, la producción de sentidos sociales y prácticas de actores, nos sumergimos en la realidad social de un pueblo con un patrimonio ambiental valioso que lo convierte en destino de residencia y turismo de montaña. El impacto migratorio es el puntapié inicial a partir del cual comenzamos a observar la conformación de tramas culturales, conflictos, interacciones y formas comunicativas. Para develarlas, nos introducimos en el estudio de los relatos identitarios de inmigrantes urbanos y de pobladores rurales autóctonos. Relatos que hablan de una pertenencia, de una historia, de una elección de vida, de una diversidad de motivaciones, trayectorias, situaciones, representaciones, perfiles, orígenes, destinos, objetivos, expectativas, experiencias y valoraciones que concurren en el hecho común de la constitución de una comunidad y sus fronteras. Testimonios que plantean "categorías con potencia identificatoria que (... ) no dejan de indicar tensiones y grados diferenciales de permeabilidad y distanciamiento social y cultural" (Merenson, 2012:49). Identidades y sentidos en disputa que, al interior de un espacio que se define como pueblo, van delineando el sentido de la comunidad.

Frente a la ausencia de propuestas integradoras dirigidas a analizar el fenómeno neorrural, en este momento, desde la teoría, nos detenemos en los conceptos más importantes para comprender un escenario heterogéneo. Aquí no nos interesa tanto la pregunta sobre cómo establecer una relación dialógica entre grupos culturales diferenciados en un mismo territorio; nos importa explorar los procesos de producción de la diferencia en el interior de espacios comunes, compartidos y conectados. En este sentido es que observamos en un espadodelocomín(1) (Trimano, 2014) el fluir de grupos que perciben y actúan de maneras disímiles porque poseen "matrices socioculturales diferentes", entendidas como el "esquema que describe los rasgos principales de la lógica de funcionamiento de un grupo o sector social, su linaje de transformaciones" (Massoni, 2013: 83). De modo tal que no solamente se trata de reconocer la diversidad de los actores, sino de reconocer sus trayectorias para hacerlos entrar en un "encuentro sociocultural situado" (Massoni, 2013). Sobre este punto vale destacar que "no hay pretensión de completitud en este poner en común 
que es el de comunicar, sino solo resonancias parciales como momentos relacionantes de la heterogeneidad sociocultural, acuerdos entre lo distinto y lo diverso colectivo" (Massoni, 2013: 181).

La localidad entendida como una "configuración cultural", en tanto que esto refiere a heterogeneidades, conflictividad, desigualdad, historicidad y poder (Grimson, 2011b), habilita las diferencias y el conflicto, y por ello postulamos que la identidad y la cultura son efectos de esa disputa. Situaciones vinculares que rastreamos en los procesos de comunicación, entre los relatos de la vida diaria, ya que surgen en las relaciones interculturales que los inmigrantes mantienen con la sociedad receptora y con otros grupos migratorios (itinerantes y turistas).

En la primera parte de este texto caracterizamos el espacio social para comprender las dinámicas locales que fluyen en la frontera rural/ urbano. Centramos el objeto de estudio: un microuniverso sociocultural constituido por interacciones, intercambios, posiciones, disputas, identidades y alteridades. La radicación de sectores de clase media y alta en una zona de características rurales, fue un indicio vital para comenzar a desentrañar las tensiones que generan ciertas presencias y dilucidar el papel de la comunicación en la constitución de una comunidad. En un segundo momento, desarrollamos un enfoque teórico tanto disciplinar, como teórico-metodológico. La perspectiva de análisis propuesta es antroposociocommicacional y tiene como base un marco interpretativo y etnográfico abierto y diversificado, plagado de préstamos, reformulaciones y contaminaciones interdisciplinarias. Lo consideramos la manera más adecuada para interpretar el significado de debates que envuelven las transformaciones de la sociedad contemporánea. En tercer lugar, describimos método y estrategias de investigación: la perspectiva etnográfica de los estudios de casos. Para finalizar, arribamos a las conclusiones que permiten no solo generar un cierre -que nunca es absoluto dado el carácter dinámico de nuestro objeto- sino reflexionar sobre nuevos ejes de debates.

\section{Sobre el pueblo y su configuración. Datos contextuales}

Las Calles es una pequeña localidad de 750 habitantes (Censo de población de 2008, Córdoba, Argentina), con un alto porcentaje de inmigrantes residentes (casi la mitad de la población), provenientes de grandes ciudades (Buenos Aires y Córdoba).

En investigaciones previas (2) confeccionamos una cartografía migracional a partir de los testimonios orales de los informantes. Allí detectamos tres flujos en la historia reciente de la migración en la localidad serrana. Cada uno de estos movimientos poblacionales (3) detenta atributos propios que se objetivan, por ejemplo, en las diquetas a partir de las cuales la sociedad receptora identifica a sus protagonistas. El primer período (1947-1970) se caracteriza por un alto flujo migratorio asociado al asentamiento inglés o anglo-argentino: en palabras nativas, los "gingos auténticos". D urante el segundo, que abarca de 1991 a 2000, dichos flujos tienen otro impulso a partir de la reedición de la categoría de "gingos" (4); aparecen en escena los "gingos" actuales una forma de sociabilidad constituida en clave de elite. En el período más reciente, del 2000 hasta la actualidad, tiene lugar una tercera ola de jóvenes cuyas razones para migrar varían desde la apuesta político-territorial al orden espiritual y religioso: los "hippies" (5); y coinciden con la llegada de empresarios del turismo. 
En esta superposición de actores, de expresiones e intereses diversos persiste un sujeto nativo, que se autodenomina "lugareño" (6) y entiende como "invasares" a quienes no son "nacidbsy ciados" (7) en el pueblo. El "luggreño" reclama para sí y para su grupo el poder comunal, un gobiemo local que siempre fue ejercido por ellos. Aun cuando las decisiones políticas sean discutidas en asambleas, hasta el momento nunca un "veridbdeafura" (8) ocupó el cargo de jefe comunal.

Es así que desde el siglo XX, gran parte de la historia de Las Calles puede leerse como una sucesión de enfrentamientos, una "rivalidad por la autoridad simbólica" (Thompson, 1995: 93) entre una cultura preexistente tradicional y una emergente innovadora (9).

La bucólica pintura del pueblo serrano se corporiza, así, en una realidad social que trama culturas, prácticas sociales y conflictos, en un espacio de interacción en donde las formas comunicativas son una manifestación, a veces ostensible, a veces velada, de sus tensiones y disputas; de las disposiciones solidarias y el diálogo, la desconfianza, la sospecha y el prejuicio.

\section{Cuestiones de método: un estudio de caso (10)}

Mediante la perspectiva etnográfica de los estudios de caso, caracterizada por una mirada reflexiva de la ciencia, el desarrollo teórico-narrativo y un predominio de categorías nativas (Neiman y Q uaranta, 2007: 219), analizamos la "neorruralidad" y las tensiones culturales entre actores emergentes (inmigrantes) y preexistentes (nativos). Las posibilidades que brinda el caso Las Calles lo transforman en una expresión paradigmática de la problemática social abordada. Su elección se fundamenta en que, a pesar de formar parte del corredor turístico cordobés, es una de las comunidades serranas de la zona menos afectada por la masificación de esta empresa y por ello buena parte de su paisaje cultural -todavía- no ha sufrido alteraciones propias del exceso de visitantes. El pueblo ubicado en el Valle de Traslasierra no posee acceso directo a la ruta, solo se puede ingresar transitando cuatro kilómetros por camino de tierra. D ebido a la ausencia de transporte público que circule por la localidad de manera frecuente, la gente recurre a otras opciones de traslado: taxis, motocicletas, autos particulares o caminando, en el caso de la mayoría de nativos. Éste constituye uno de los principales motivos por el cual el sitio atraviesa un proceso incipiente y paulatino de transformación social, que merece ser analizado. Al compararlo con poblaciones aledañas, como Mina Clavero y Nono, mejor comunicadas, se observa que éstas han recibido mayor impacto de migración urbana en los últimos diez años.

Esta investigación cualitativa tuvo por objeto la producción de sentidos sociales y el repertorio de prácticas de actores que migran de la ciudad al campo. El contenido para analizar la "neorruralidad" fue obtenido por medio del trabajo etnográfico; se realizaron entrevistas no estructuradas in situ que se complementaron con observación no participante. Se conformó una muestra intencional de jóvenes y adultos (11) nativos e inmigrantes residentes en la localidad serrana. La selección considero el tiempo de residencia de los actores, sus anclajes y trayectorias. Para profundizar ejes de indagación, los "neorrurales" se caracterizaron bajo tipificaciones sociales ("hippies" y "gingos") que fueron redefiniéndose a partir del campo y durante la investigación. El número de entrevistas se determinó a través del muestreo por 
saturación teórica o "muestreo teórico" (Glaser y Strauss, 1967), considerando los criterios de "propósito teórico" y "relevancia" (Jones \&al, 2007).

\section{Una mirada antroposociocomunicacional: transdisciplina, teoría y enfoque metodológico}

En este trabajo, cómo ya lo hemos advertido, presentamos aspectos conceptuales que iluminan la construcción de la "neorruralidad" como tendana redadara de un proceso social, demográfico, cultural, económico y político de reestructuración espacial y simbólica del campo y la ciudad (Trimano, 2014). La propuesta es considerarla como una construcción autónoma, un emegenteheterogéneo corolario de procesos de interpenetración y coexistencia de contrarios, que atiende a una alternativa de vida crítica con el modelo urbano y a una perspectiva sobre el cambio rural.

Las particularidades del escenario de estudio retratado permiten de manera empírica señalar que la "neorruralidad" es una tendana de movilidad poblacional y residencial. La gente se traslada desde áreas urbanas, generalmente grandes ciudades, hacia pequeños asentamientos en áreas rurales. Este flujo migratorio es protagonizado fundamentalmente- por personas de entre 30 y 60 años de edad, de clase media y media alta. En su mayoría son profesionales y rechazan a la sociedad urbana y de consumo. Una vez instalados en áreas rurales, generalmente alejadas y en despoblamiento, se insertan en la vida institucional de las comunidades (escuelas y espacios recreativos) promoviendo una rehabilitación simbólica de dichos espacios. Aunque resulte contradictorio, todo esto genera relaciones conflictivas con aquellos que se sienten auténticos poseedores del territorio: los lugareños, aquellos "nadidos y ciadbs" en un pueblo que, según entienden, forjaron con sus propias manos. Esta es la actitud defensiva de la sociedad receptora, que busca una supeionidad desada y por tanto preservar su identidad frente a nuevas presencias en el territorio. El resultado es una trama cultural definida en el conflicto que puede interpretarse al prestar atención a un enjambre de relaciones identitarias en tensión (Trimano, 2014).

Empaquetar un fenómeno multidimensional en un solo concepto se vuelve un ejercicio complejo, por ello es necesario recalcar que los sentidos que cobra la migración de la ciudad al campo y las nuevas preferencias residenciales nos interpelan acerca de una vida crítica y alternativa al modelo urbano y sobre la naturaleza de lo rural.

A pesar de que las migraciones han estado presentes en todas las épocas, y quizá hasta en proporciones mayores que en la actualidad, su sentido cultural cambia y se transforma todo el tiempo. Cambian los destinos de los migrantes y con ello sus prácticas, temporalidades y sentidos de territorialidad. De este modo, como plantea Héctor Schmucler (1997), establecemos conceptualmente una barra entre los términos "comunicación/ cultura", generándose así una fusión tensa entre elementos distintos de un mismo campo semántico. "La barra acepta la distinción, pero anuncia la imposibilidad de un tratamiento por separado" (p.149).

En definitiva, la comunicación, en tanto representaciones, prácticas sociales y procesos culturales, es el lugar desde el que miramos la trama de la vida cotidiana de esta localidad impactada por la migración urbana. Una trama que involucra 
dimensiones emocionales, intelectuales, afectivas, prejuicios, estereotipos, normativas, pasado y presente. Comprendemos a Las Calles como una comunidad configurada por tensiones y negociaciones identitarias, un lugar de concertación entre "veridos deafuea" (inmigrantes urbanos) y "lugareños" que interactúan. Primero, porque comparten un mismo territorio y segundo, ciertos intereses -en disputa- por la posesión, uso y control del espacio-tiempo-pueblo.

A partir del análisis de las representaciones sociales (RS) (Jodelet, 1968; Hall, 1997) y las prácticas de los actores, prestamos especial atención a la densidad sociocultural de sus negociaciones, conflictos e intercambios; todos ellos mediados por la desconfianza, las relaciones de poder y las asimetrías que dificultan el mutuo entendimiento.

Mediante la producción de RS, los grupos materializan procesos de diferenciación social (acentúan sus relaciones marcándolas con la hostilidad, la extrañeza generalizada, el cálculo o la indiferencia). El mutuo entendimiento se ve así, distorsionado, por depender de la dimensión oculta de las formas de percepción materializadas en la presencia de pautas culturales a través de los actos de comunicación. La densidad comunicativa de la experiencia rural aparece tanto en el idioma del estigma con que los urbanos cargan al otro, como en el de la réplica con que el "lugareño" reasume su alteridad y se afirma, transformando esta situación -que puede darse en un simple encuentro en el bar o almacén del pueblo- en un espacio de interlocución de identidades. Dichas transformaciones condicionan las prácticas sociales (Bourdieu, 2007) y los habitus de los agentes que ocupan determinadas posiciones en el campo. Tratar el concepto de habitus amplía el análisis y permite relacionar el discurso con sus condiciones de producción; las situaciones grupales 0 individuales en las que se producen 0 la posición en el espacio social de los enunciadores (Kornblit, 2007:11).

Al poner de relieve la producción de sentido perpetrada por grupos con universos perceptivos diversos (preexistentes y emergentes), se toma como punto de partida la comunicación en sentido amplio; esto quiere decir, considerando no solo los gestos, las palabras y las relaciones inter e intra personales, sino también la puesta en comunicación de tiempos muy distintos: el inmemorial de la tierra, y el vertiginoso de la urbe. Referencias a un "lenguaje silencioso" (Hall, 1989) en el que, sin necesitar deliberadamente de las palabras, se crea un lazo compartido entre los miembros de la comunidad.

El concepto de comunicación, en este marco, se vincula a "un proceso de interacción simbólica que puede implicar la puesta en juego de dos o más estructuras de significación" (Grimson, 2011a:21). Se entiende por esto la construcción y apropiación de sentido de la vida cotidiana que aquí abarca tanto a las relaciones interpersonales (Grimson, 2011a) como las que se mantienen con el entorno natural.

En el espacio público de la comuna detectamos que los sentidos producidos en cada acto y los significados que los actores otorgan a los significantes lingüísticos, proxémicos y kinésicos dependen de conjuntos de acuerdos y presupuestos más 0 menos instituidos en la cultura. Pero, al mismo tiempo, ese espacio arquetípico, nos devuelve una certeza: "en situaciones de interculturalidad un mismo discurso puede ser interpretado de maneras múltiples e incluso contrapuestas" (G rimson, 2011a: 21). 
En efecto, una mirada desde la "comunicación/cultura" trasciende los límites impuestos por los compartimentos estancos disciplinares y concibe a la comunicación como un espacio de articulaciones donde dialogan distintos campos del conocimiento social. En esta investigación, utilizamos la transdisciplinariedad y destacamos el predominio de una articulación particular entre antropología, sociología y comunicación que se impregnan en un enfoque antrqposococommicaional único (Trimano, 2014). Tratamos de no incurrir en uno de los mayores problemas en que generalmente recae la lógica disciplinaria: imprimir direccionalidad a las investigaciones dejando de lado el lugar que los actores -involucrados en la investigación- le otorgan a ese mismo objeto (Grimson, 2011a). Efectuamos un doble registro que, unido, permite un movimiento de indagación y estudio suficiente de la realidad desafiada: por un lado, la preocupación por la dimensión objetiva que da origen a las tensiones, conflictos e interacciones; y por el otro (unida) la dimensión subjetiva, aquello que da forma a la percepción de los diferentes actores y permite poner en escena las figuras en que se hacen visibles las estructuras y estrategias del poder, las prácticas y las representaciones que de este acontecer se hacen los protagonistas.

Tanto en el aspecto teórico, como en el metodológico, nos cuestionamos y penetramos en un ambiente más bien desconocido que novedoso. Nos replanteamos la relación entre ciencias sociales y estudios de comunicación. Adoptamos una perspectiva particular que brega por la necesidad de introducir en la comprensión de los procesos comunicacionales, el estudio de la dimensión espacial y temporal y la perspectiva del actor con sus continuidades, rupturas, ambigüedades y contradicciones.

En concreto, consideramos necesario el enfoque antroposoiccommicadional por su cualidad de apertura, entendiendo por ello una actitud favorable a la innovación. En este sentido, y para tratar de reducir a la mínima expresión los obstáculos disciplinarios, buscamos con la metodología antropológica, realizar el trabajo de campo y sumergirnos en el mundo del extrañamiento y la familiarización. Combinamos el punto de vista analítico de la comunicación, basado en la dimensión simbólica de la sociedad (producción de signos, símbolos, sentidos, prácticas) y el análisis sociológico de los testimonios producidos por los inmigrantes urbanos y los pobladores "luggreños". D ejamos de lado el tabú de las fronteras disciplinarias y nos asomamos a la permeabilidad, a los intersticios, a los puntos de cruce entre especialidades en pos de alentar la creatividad y el descubrir-nos. En esta línea, G eertz (1991) advierte con certeza que "las descripciones [de quien hace etnografía] presentan al espíritu sociológico material concreto con que alimentarse" (p.34) o actualizarse. La interpretación cultural necesita que "la teoría permanezca más cerca del terreno estudiado" (p.35).

Por lo dicho, nos apropiamos de las palabras de Martín-Barbero (en Reguillo, 2005) no por ambiciosas sino por certeras, quien sostiene que los estudios socioculturales de la comunicación desafían en un reto los compartimentos de las ciencias sociales. Así, un enfoque de esta magnitud permite, no solo invitar a las disciplinas a una experiencia conjunta, donde cada una desde su óptica y conscientes de sus limitaciones, advierta a la otra acerca de cómo ir develando el objeto, sino también simultáneamente enfrentarlas a la superación de algunas limitaciones: 
A la sociología, planteándole la imposibilidad de comprender el sentido de la ación đedetiva por fuera del proceso de constitución de los sujetos sociales, esto es, de la construcción de identidades. [Lo que implica que dicha disciplina se replantee la incorporación] de los relatos en que se teje el mito que funda y sustenta al nosotros, y los discursos en que se materializa la lucha por la hegemonía del sentido [como objetos propios]. (... ) [Y a la antropología, esta investigación] la enfrenta a la necesidad ineludible de superar el populismo indigenista para que se haga cargo de las (... ) (Martín-Barbero en Reguillo, 2005: 12-13);

... configuraciones y el destiempo en el que incurre la dicotomía campo-ciudad, ya un anacronismo. Es en las reapropiaciones que tanto "lugareños" como citadinos en unidad realizan de dicha división, donde comenzamos a divisar las inconsistencias del pensar lo rural y lo urbano como órdenes distintos.

\subsection{Comunicación, fronteras y configuraciones}

La cultura como proceso y forma de vida es un espacio y espectro simultáneamente material y simbólico donde los actores sociales tejen tramas de significación y transcurren en su ser y estar. Pero sobre todo, es un espacio de disputa, de diferencia; una construcción que se da en el conflicto, una arena de tensiones y valores (Trimano, 2014). Por ello, frente a las visiones que conciben a la cultura como homogénea y a las propuestas que -como esa homogeneidad no se verifica- infieren que el concepto debe ser desechado, recurrimos a la noción de "configuración cultural", caracterizada por "la heterogeneidad, la conflictividad, la desigualdad, la historicidad y el poder" (G rimson, 2011b). Esta es la manera para dar cuenta porqué "paisas", "lugareños", "hippies" o "gingos" (12) tienen sentido en el espacio social que estudiamos y no en otro.

En este sentido, E.P. Thompson (1995) permite pensar la cultura como una forma de vida en común; pero fundamentalmente como una palestra de elementos conflictivos en la que intereses opuestos ejercen reclamaciones contrarias. El historiador inglés advierte sobre las contradicciones, fracturas y oposiciones que puede encubrir el término cultura al estudiarse una comunidad.

La perspectiva culturalista clásica planteaba que el mundo estaba constituido por diferentes culturas, "cada una de las cuales tenía una relativa homogeneidad, sus fronteras más o menos claras y una identidad propia" (Grimson, 2011b:20). Esta concepción anuda las nociones de territorio, sociedad, comunidad, identidad y cultura; y esta última aparece como algo localizado.

$\mathrm{Si}$ imaginamos esta matriz de pensamiento aplicada a la localidad de estudio, un objeto complejo y cruzado por múltiples problemáticas, los síntomas de anomalía serían tales que habríamos acabado estudiando una excepción, una deformación. No debemos irnos tan lejos para atribuirle vigencia a esta imagen. La idea de que cada país detenta una cultura y una sociedad "propias y distintivas (... ) se asume tan naturalmente, que los términos 'cultura' y 'sociedad' suelen anexarse sin más a los nombres de los estados-nación; así, un turista visita la India para comprender 'la cultura india'..." (G upta y Ferguson, 2008: 235). La fijeza de las fronteras cosifica a 
los grupos humanos presuponiéndose la existencia de una esencia cultural, que deviene en la reificación de los procesos históricos. Para esta perspectiva, la identidad se deriva simplemente de la cultura.

Durante el siglo XX se produce un fuerte desplazamiento en el trabajo antropológico. De la representación gráfica del mapa y el mundo fragmentado en distintas culturas puras, nos trasladamos velozmente, bajo el efecto de un barrido fotográfico, a "la compresión espacio-temporal del planeta" (Harvey, 1998). Esta nueva experiencia del mundo volvió inviable la interpretación de las culturas como mundos distantes. "La certeza acerca del espacio y el tiempo absolutos dio lugar a las inseguridades de un espacio relativo en transformación, en el cual los acontecimientos de un lugar podían tener efectos inmediatos y ramificados en muchos otros lugares" (Harvey, 1998: 289). Entonces, surgió una crítica que ponía el acento en "la circulación, la permeabilidad, el carácter borroso de las fronteras e híbrido de las culturas" (G rimson, 2011b:22).

Desde una perspectiva posmoderna, algunos críticos consideraron que la cultura implicaba producir alteridades y fabricar fronteras, pero comenzaron a estudiarse interconexiones como si se produjeran únicamente entre individuos y no se consideraba a las mediaciones o marcos culturales. Se dio inicio a un pensamiento de "la 'cultura' no tanto como un sistema de significados o incluso como una forma de vida, sino como algo cuyos elementos son financiados, producidos, censurados y retransmitidos a través de una nación, 0 incluso más allá de las fronteras nacionales"(Abu-Lughod, 2006: 132).

El problema de las diversas perspectivas que abordaron y abordan la cultura radica en entender el cambio social y las transformaciones culturales como algo situado en espacios interconectados.

Pasear por las retóricas homogeneizantes de la antropología clásica, hasta el proyecto teórico y político posmoderno, proporciona un panorama acerca de la noción de cultura que ha circulado con el trascurrir de los años. La comunidad de estudio no puede ser entendida ni como cultura esencial, ni como fragmentos diversos que podrían ficcionalizarse en una totalidad. Por el contrario, existen representaciones, prácticas e instituciones posibles e imposibles y algunas que llegan a ser hegemónicas (Grimson 2011b). Hay valores distintos para el pasado o el futuro, diversas temporalidades y territorialidades. Los grupos manifiestan sus demandas, identificándose públicamente de cierto modo; y ello porque el conflicto social inherente a toda configuración- se despliega a partir de modalidades propias de un lugar, mientras que otras formas permanecen obstruidas.

Los valores del trabajo o las costumbres alimenticias también presentan variaciones en la concepción de distintos grupos. Sucede lo mismo con el saludo, su ausencia es socialmente intolerable para los "luggreños" y no una mera falta de cortesía. Se trataría de "escasez de respeto" (Sennett, 2003), de la anulación, invisibilización de la condición de otro como persona. En cambio, en el espacio de una ciudad, no saludar a desconocidos es una práctica normal, lo anómalo sería estar dirigiéndose a todos aquellos que no conocemos. Los modos en que el saludo es significado y las reacciones sociales que suscita son muy distintas y se insertan en regímenes de significación específicos. 
Los actores adquieren un lenguaje para clasificarse, ya sea por sus rasgos físicos, sus costumbres o hábitos de vida y las diferencias se utilizan para imaginar fronteras. A través de éstas, amparados en los capitales que detentan, cada uno emana su poder en el marco de la relación que establecen. Las tipificaciones "paisa" y "hippie" organizan la vida del pueblo y son posibles en dicha configuración, mientras que en cualquier otro sitio no significarían lo mismo, o no existirían o tomarían otra forma.

Las partes, con sus papeles, no pueden ser analizadas separadamente porque la "contienda simbólica" (Thompson, 1995) adquiere su sentido dentro de un equilibrio determinado de relaciones sociales. Y, puesto que la constitución de un todo debería implicar que las partes no se ignoren, muchas veces la ignorancia es una forma de interacción que no debemos descuidar. Una "configuración cultural" es una totalidad conformada por partes diferentes que tienen relaciones entre sí y una específica "lógica de interrelación" (G rimson, 2011b). Al analizar las relaciones entre "lugareños" y "veridbs de afuea" o inmigrantes nos encontramos "no tanto con una reñida e inflexible batalla entre antagonistas irreconciliables, sino con un 'campo de fuerzas' social" (Thompson 1995: 91) donde los actores se alían, se enfrentan y negocian. Al participar de una disputa sus acciones entran en una lógica compartida que les permite pertenecer, al menos parcialmente, a mundos imaginativos similares (Grimson 2011b). El análisis de la cultura habilita, entonces, pares enfrentados y lo que tienen en común. Si la configuración implica una "trama simbólica común" debe existir inteligibilidad, es decir, lenguajes para entenderse y enfrentarse. Más allá de que las interpretaciones sobre los mismos enunciados sean diferentes, los sujetos comparten los "'principios de (di) visión' del mundo" (Grimson 2011b:176) (campo/ ciudad, culto/ popular, etc.) y una lógica sedimentada de la heterogeneidad que habilita e inhabilita posiciones de sujeto y lugares de enunciación. Lo "compartido" amalgamaría los aspectos culturales propios de cada grupo, los que comparten en la diferencia y la igualdad, en el sedimento y en el bullir de la novedad en un espacio-temporal.

Grimson (2011b) recupera la crítica de Raymond Williams a la tradición filosófica occidental, según la cual es necesario dejar de pensar la cultura como una esfera de la vida ya que todo proceso social detenta significación. Esto no impide que funcionen como dominios separados en la vida social y "lo que se ha fabricado existe. Pero lo que ha sedimentado también puede ser intencionalmente socavado y puesto en cuestión" (p.42). Las relaciones de desigualdad sedimentadas -las más visibles aquí de clase, de género y de localía- son invenciones que quizá ya fueron creadas por otros, pero puesto que los actores hacen su propia historia, esas redes pueden ser modificadas en función del poder y la capacidad de los protagonistas.

Analizar las articulaciones que hacen posible una configuración cultural permite comprender su contingencia y pensarla como un proceso de constitución de hegemonía. Por esta razón, la cultura no es un anexo o una esfera interesante, sino una trama donde se producen disputas cruciales sobre las desigualdades $(. . .)^{\prime \prime}$ (Grimson, 2011b: 41), sus legitimaciones y las posibilidades de transformación.

La noción de cultura como configuración habilita a la lectura de un contexto de interculturalidad, entendido como una multiplicidad que interactúa. La interacción no anula la diferencia, ésta "se produce en la interacción, así como en las intersecciones se producen las apropiaciones, las resignificaciones, las combinatorias, las asimilaciones y las resistencias" (G rimson, 2011b: 238). Al mismo tiempo, permite comenzar a saldar la consolidada dicotomía rural-urbana. 


\subsection{Fronteras simbólicas y de las identificaciones}

En la convivencia cotidiana del pueblo, la frontera se vincula con todo aquello que separa (espacios, prácticas, valores, símbolos), con los límites, como con lo que se articula en el marco de alteridades en tensión. La conjunción "nos/ otros" es un lugar construido para pensar. Comprender al otro, es una condición necesaria para entendemos a nosotros mismos (Grimson, Merenson y Noel, 2011). "Las articulaciones y desajustes entre diferencia y desigualdad son una de las claves de la frontera" (G rimson, 2011b: 129). Hay diferencia por desigualdad cuando el lenguaje de las identificaciones utiliza la sintaxis de la exclusión.

La multiplicidad de fronteras se da entonces, entre personas que habitan el mismo pueblo; este es el límite de la identidad cultural. La construcción de la imagen de un "nosotros" requiere la de un "otro" diferente pero próximo. Se trata de fronteras de significados, donde un estilo de vestir, de caminar o un color de piel cambian drásticamente de sentido según quien lo detente. "La comunicación entre dos grupos puede ser el proceso que les permite distinguirse uno del otro" (G rimson, 2011b: 131). D e esto ya habla G eorge Simmel (1986) cuando sostiene que para conducirse, el hombre se capta a él mismo y a los otros en función de "tipos". La mirada del otro, al mismo tiempo que completa, nos convierte en algo que no somos, en ciertos tipos sociales. La figura del "extranjero" otorga forma a la frontera de lo social; para que exista un "nosotros" tiene que haber una distancia con el otro, con aquello que marca o nos muestra lo que no somos. Las fronteras simbólicas, materializadas en la construcción de ciertas clasificaciones, producen un distanciamiento del "otro", una manera de relación y una construcción. Hacer cuerpo al "otro" mediante una tipificación es ingresar en una dinámica de exclusión/ inclusión pero espećficamente de incorporación del "otro" a nuestras vidas.

El problema teórico que plantea G rimson (2010) "deriva del hecho empíricamente constatable de que las fronteras de la cultura no siempre coinciden con las fronteras de la identidad" (p.3). Ello porque en "la medida en que las identidades son construidas, inventadas, manipulables, pueden postular la existencia de fronteras culturales que no siempre son empíricamente verificables" (G rimson, 2010:10). Allí hay fronteras de las culturas y fronteras de las identidades. En esta línea, la identidad es un efecto de la disputa; y por tanto son mucho menos fijas - casi nada- de lo que pretendían las aproximaciones estáticas y tipologizantes de la antropología clásica.

La noción de identidad aquí se entiende desde una "concepción relacional y situacional" (Cuche, 2002); es decir se establece a partir de un vínculo con el otro. Dicho así

... una cultura particular no produce por sí misma una identidad diferenciada: solo puede ser el resultado de las interacciones entre los grupos y de los procedimientos de diferenciación que instauran en sus relaciones (... ). La identidad se construye y se reconstruye constantemente en los intercambios sociales. (Cuche, 2002:110) 
Para nuestro trabajo, acotamos la acepción de identidad a las clasificaciones de grupos sociales y a los sentimientos de pertenencia o identificación a un determinado grupo. Se trata de una construcción siempre en construcción.

Como todas las prácticas significantes, está sujeta al 'juego' de la différance Obedece a la lógica del más de uno. Y puesto que como proceso actúa a través de la diferencia, entraña un trabajo discursivo, la marcación y ratificación de límites simbólicos, la producción de "efectos de frontera". Necesita lo que queda afuera, su exterior constitutivo, para consolidar el proceso. (Hall, 2003: 15-16)

Al igual que lo planteamos en la noción de cultura, el concepto de identidad aquí propuesto no es esencialista, sino estratégico y situado. Se construye en un proceso y de múltiples maneras a través de representaciones, prácticas y posiciones emergentes y sedimentadas, diferentes, muchas veces cruzadas y antagónicas.

Para los "lugareños", la presencia de los "veridbs deafura" no implica un retorno a las raíces, sino una aceptación del sentido que cobran sus derroteros. Hemos detectado, a través del trabajo etnográfico, que una vez en el territorio, en tanto vecinos, los sujetos en cuestión, justamente por el hecho de compartir ese contexto social e histórico, fabrican con material tradicional y emergente una "'caja de herramientas identitarias', un conjunto de clasificaciones disponibles con las cuales sus miembros pueden identificarse a sí mismos e identificar a los otros" (Grimson, 2010:11). A través de esas categorías, podemos observar cómo dicha sociedad se piensa a sí misma y cómo sus miembros actúan y se determinan frente a los otros. "Esas clasificaciones hablan, así, de una historia social, cultural y política incorporada en el sentido común" (G rimson, 2010: 12).

Pero las categorías identitarias no sólo se emplean por los pobladores para representarse de manera mutua -material que luego nosotros utilizamos para describir a la sociedad- o para aludir a su pertenencia o identificarse. Simultáneamente, permite a estos actores afiliarse y desafiliarse del grupo, estigmatizar y ser estigmatizado en un círculo de desigualdades y jerarquías. "Esas disputas son factibles porque se comparten las categorías, porque los significantes se anudan a algún significado (... ). Ese compartir un territorio de diferencia, de conflicto, una arena que es histórica, está vinculado a la noción de cultura" (G rimson, 2010: 12).

Las diferencias entonces se construyen mediante las representaciones, pero también mediante prácticas de acercamiento y distanciamiento. Para decirlo en términos de Bourdieu, las diferencias se corresponden a clases reales que exigen como condición de posibilidad precisamente una similitud de condiciones y condicionamientos sociales (1997: 22) que tienen lugar en la experiencia del espacio pueblo.

\subsection{La comunicación: el espacio de lo común y "el espacio público muerto"}

En este estado de cosas, como lo hemos advertido, la cultura y la identidad son el resultado de procesos de comunicación, se configuran en el espesor cultural de la comunicación. Por su parte, las identidades necesitan corporizarse. Parafraseando a Rossana Reguillo (1996), la identidad asumida se "comunica" y al comunicarse el 
grupo aprende de sí mismo y de los otros. Es en el marco de este proceso que la identidad se objetiva, se muestra, es real.

Las relaciones entre las personas, aquí, son inseparables del espacio social en el que tienen lugar. Partiendo de la premisa de que el espacio social es la materialización de la existencia humana, como sostiene Henri Lefebvre (1991: 202) retomamos algunas categorías propuestas por Renato Ortiz (2005), reinventándolas.

Cuando nos referimos a lo "local", no imaginamos "un espacio restringido, bien delimitado dentro del cual se desenvuelve la vida de un grupo o conjunto de personas" (Ortiz, 2005: 56); sino más bien un lugar plagado de porosidades, ilimitado, donde tiene lugar la vida de un conjunto de áralos en cuyo interior se desarrolla una sociabilidad del "entre nos" (Svampa, 2008) y por ello temporalidades y territorialidades. Si bien este lugar se inscribe dentro del ámbito de lo familiar, no es la proximidad lo que reconforta la relación entre círculos, sino el conflicto y la distancia con un predominio del "modelo de murmuración" (Sennett, 2002). Sobre este último podemos decir que "la chismografía constituye un intercambio irrestricto de información acerca de otras gentes; sus pecados, asuntos amorosos o pretensiones (... ) [porque en el pueblo] estas intimidades constituyen el conocimiento común" (Sennett, 2002:146). En estas condiciones, la conversación sobre la personalidad puede ser una de las maneras de establecer el primer contacto con los demás (Sennett, 2002:148). La proximidad es lo que se da hacia el interior de cada círculo. Y el debate por las identidades está atravesado en estos términos y ya no por su relación directa con el suelo en que está inserta. Por eso hablar de círculos nos permite establecer hacia el interior del contexto-pueblo un ordenamiento entre espacios territoriales y simbólicos diferenciados que confrontan entre sí.

La localidad que nos convoca constituye un medio donde los extraños se encuentran; en efecto se trata de un lugar erigido sobre la corriente conjunta de esos tropiezos ya que "ha crecido merced a la migración de cantidades desconocidas" (Sennett, 2002:124). En torno a esta figura, Sennett (2002) dibuja una diferencia: el extrañoforastero es aquel a quien se puede identificar, por ejemplo como urbano, en el marco del pueblo y establecer que no pertenece a ese paisaje. Las diferencias que se suministran son inmediatas. Los extraños son interpretados a través de estereotipos y rechazados como inadaptados o peligrosos de conocer debido a las connotaciones negativas implicadas en esta valoración (Sennett, 2002: 124). Otro sentido se le atribuye al extraño-desconocido, para quien no se tiene una etiqueta clara donde ubicarlo. -Estas expresiones encarnan el sedimento de experiencias pasadas, a través de las cuales, hoy, se establece un tipo de comunicación con los nuevos pobladores.

El problema no implica sólo una cuestión de crecimiento poblacional; sino que especifica un hecho social determinado: "cuando el pueblo creció, su población se volvió problemática" (Sennett, 2002:125). Este hecho es traducible en "el problema de vivir con un extraño o ser un extraño" (Sennett, 2002:133). En el caso de los inmigrantes el asunto sería "cómo provocar la creencia entre aquellos que no nos conocen. (... ) Para que un forastero suscite dicha creencia debe atravesar una barrera y hacerse creíble según los términos familiares utilizados por aquellos que están en el interior" (Sennett, 2002: 117).

Los flujos migratorios en la localidad fueron debilitando "cualquier tipo de confianza que la gente pudiese depositar en la clasificación natural, rutinaria, de los demás 
según fuese su origen, sus antecedentes familiares o su ocupación" (Sennett, 2002: 142). El intento de darle una forma a estos intercambios sociales (Sennett, 2002: 142), es un esfuerzo por crear un significativo sentido en torno a un espadodelocomún comunal; éste comienza a tejerse a partir de considerar "los saludos, presentaciones y chismografía como el primer estadio de la sociabilidad [entre] extraños que se encuentran" (Sennett, 2002:142). El problema se presenta cuando el vínculo social inicial no es establecido -al menos por una de las partes- mediante formas de cortesía basadas en el reconocimiento de la gente desconocida. Esta situación convierte la experiencia impersonal en insensata y la complejidad social en una amenaza inmanejable (Sennett, 2002).

El propio extraño representa una figura amenazadora y pocas personas ipueden disfrutar plenamente? [La interrogación es nuestra] en ese mundo de extraños (Sennett, 2002: 20) en el que se instituye la comunidad. La importancia de la categoría de "extraño" radica no solo en la determinación del "otro", y en el autodescubrimiento mutuo, sino en el develamiento -individual y grupal- de otra manera de fijar los términos del encuentro entre los sujetos.

Se trata de tomar al pueblo, dice Michel Maffesoli (2004) como "entidad contradictorial; o también como práctica cotidiana en la que el 'mal', el extranjero, el prójimo ya no sean exorcizados, sino integrados según medidas y pautas variables, aun cuando éstas fueran homeopáticas" (p.208). A este respecto, el autor agrega que el problema que se plantea a nuestras sociedades es el de equilibrar las pasiones que se oponen y cuyo antagonismo se acentúa desde el momento en que se reconoce una pluralidad de naturaleza, una pluralidad de naturalezas (p.209). Es en este sentido que acuña el término "armonía conflictual" (p.86), para referirse a que tanto en la vida cotidiana como la pública, los sujetos son guiados más por la pasión que por la razón; siendo difícil pensar a partir de la idea de equilibrio una comunidad.

Venimos haciendo referencia al "aislamiento" que, en términos de Sennett (2002), puede ser utilizado en tres sentidos que aquí adaptamos a los fines de una interpretación propia. Primero, significa que los habitantes de la estructura rural

... se ven inhibidos para sentir cualquier relación con el medio en el cual se emplaza la estructura. Segundo, que en la medida en que uno pueda aislarse en un automóvil ${ }^{1}$ particular para disponer de libertad de movimiento, deja de creer que el medio pueda tener algún significado, salvo como una forma de lograr el objetivo del movimiento propio. Y un tercer sentido de aislamiento social en espacios públicos (... ) que es el que se produce directamente por la visibilidad que los demás tienen de uno. (p.44)

[Cuando se tiene] "al otro bajo vigilancia, la sociabilidad decrece y el silencio constituye la única forma de protección” (Sennett, 2002:44).

Como supuesto, entonces, podríamos argumentar que el impacto de la migración en el pueblo produce el desgaste del sentido de la vida (y la vía) pública como espacio de encuentro; y ello debido a que "el sistema de expresión pública se transforma en un sistema de representación personal" (Sennett, 2002:67). Las condiciones materiales 
de la vida hacen que la gente se interrogue sobre los demás; y esta incertidumbre no es una cuestión emocionalmente neutra (Sennett, 2002:149): el temor al desconocido está siempre latente. Viene a ser la sobreimposición del mundo privado sobre el epaciodelocamín

A través del interrogante "¿Cómo puede evitar la gente ser examinada?" Sennett (2002:68) -desde el relato de experiencias vividas por el hombre burgués en el siglo XIX-nos estimula a imaginar que la única defensa segura de los actores sería la de tratar de impedir el sentimiento, no tener ningún sentimiento que mostrar. Dicha retirada sería el único medio para que ellos mantengan alguna medida de invulnerabilidad (Sennett, 2002: 68). Por ejemplo, los "veridbs deafuea", tratando de ocultar al resto de los personas cualquier tipo de vestimenta que pueda ostentar 0 llamar la atención. De este modo, tratarían de evitar ser descubiertos como personas por medio de la supresión de los sentimientos (Sennett, 2002:69). Entonces, el silencio (el no mostrarse) en público sería el único acto comunicativo o camino por el que podrían experimentar la vida pública, especialmente, la vida de la calle, sin sentirse abrumados (Sennett, 2002: 69). No obstante, este muro invisible y silencioso significaría que el conocimiento en público es una cuestión de observación de escenas, de otros hombres y mujeres, de nativos y migrantes; anulándose el conocimiento a partir del intercambio social. Con ello los sujetos estarían optando decididamente a permanecer como extraños entre sí.

Mientras tanto, a partir de Maffesoli (2008) se nos ocurre que la "supresión del sentimiento" que retomamos de Sennett (2002) y reinventamos como una forma de sociabilidad, puede ser complementada y recreada desde la idea de "circo y círculo". El espectáculo de atuendos y silencios truculentos garantiza, "bajo sus distintas modulaciones, una función de comunión" (Maffesoli, 2008:153). Es la teatralidad del circo y del círculo, lo que caracteriza otro aspecto de la socialidad: el de "religación" (volver a ligar) para describir el lazo orgánico en el cual interactúan la naturaleza, la sociedad y los grupos (Maffesoli, 2008:153). Este hecho cultural se inscribe en una lógica comunicacional muy presente en las sociedades actuales: tanto el lenguaje verbal como no verbal constituyen una amplia red que liga a los individuos entre sí. En este suceder, las "situaciones silenciosas" (Maffesoli, 2008) toman las riendas del estatuto del vínculo social.

Una comunidad es una identidad colectiva; es una manera de decir quiénes somos "nosotros" (Sennett, 2002). Es decir, la comunidad se transforma en un fenómeno del ser colectivo más que en una acción colectiva. "La única transacción en la que el grupo se compromete es en la purificación, en el rechazo y castigo de aquellos que no son como [nosotros]" (p. 494). Suceder fundado en la verosimilitud de las apariencias, en la lógica del símbolo como emblema de defensa local contra el mundo exterior. Por este motivo, la falta de una cultura impersonal fuerte en el poblado despierta entre la gente una pasión por la revelación íntima fantaseada.

Cuanto más se transforma el mito de la impersonalidad vacía, en sus formas populares, en el sentido común de una sociedad, más moralmente justificadas se sentirán las masas al destruir la esencia de la cultura, que significa que los hombres pueden actuar juntos sin la compulsión de ser iguales. (p. 563) 
Maffesoli (2008) afirma que aunque no sea más que una metáfora, se podría resumir esta situación hablando de una "multitud de aldeas" (Beauchard, 1985:25 en Maffesoli) que se entrecruzan, se oponen, se ayudan mutuamente, sin dejar de ser ellas mismas (p.242). Así, el objeto pueblo puede ser abordado como "una sucesión de territorios [y temporalidades] (debido a que cada conjunto genera su propia construcción del espacio y el tiempo y con ello una propia sociabilidad) en donde la gente, de manera más o menos efímera, se arraiga, se repliega y busca cobijo y seguridad" (p.243). El término aldea remite tanto a un espacio concreto como a un territorio simbólico, de cualquier especie, que permite a un "'cuerpo' social existir como tal" (p.243). Inspirado en Simmel, el autor propone observar la forma del "vínculo de reciprocidad" que se entreteje entre los individuos:

\begin{abstract}
Se trata, en cierto modo, de un vínculo en donde el entrecruzamiento de las acciones, de las situaciones, de los afectos forma un todo. De ahí la metáfora: dinámica del tejer y estática del tejido social. Así, al igual que la foma artísticase crea a partir de la multiplicidad de los fenómenos reales o fantasmáticos, de la misma manera la foma soiłal podría ser una creación específica a partir de los hechos minúsculos que componen la vida común y corriente. (2008: 159)
\end{abstract}

En este orden de ideas, si la "tribu", en términos de Maffesoli (nosotros preferimos hablar de círculo) es la garantía de la solidaridad, no se puede descuidar -en línea directa con el planteo de Sennett párrafos arriba- que también es la posibilidad del control y por ello fuente de prejuicio y ostracismo pueblerino. "Ser miembro de una tribu puede llevar a sacrificarse por el prójimo, pero también a no tener más apertura mental que la que provoca el chauvinismo del dueño de un negocio" (Maffesoli, 2008:184). "El desarrollo de esta intolerancia no es el producto de (... ) la arrogancia o de la autoseguridad del grupo. Se trata de un proceso más frágil en que la comunidad existe solo mediante una continua simulación de las emociones" (Sennett, 2002:672).

El pueblo fronterizo es escenario de un sinfín de fusiones, desequilibrios e inquietudes semejantes a los movimientos poblacionales que acoge. La exogamia que ello suscita da como resultado la creación de un lugar original, bien representado en la expresión contradictoria propuesta por Maffesoli (2008) de "arraigamiento dinámico". Esta referencia refleja una manera de vivir la heterogeneidad como "energía contenida en la necesidad del exceso, del desorden, necesidad de lo que viene a romper con el encierro, en las sociedades demasiado ensimismadas; en una lógica de ruptura analítica" (p.19). El autor deja abierta otra posibilidad para mirar nuestro objeto: "utilizar las pasiones (reprobadas) tal y como la naturaleza las da, y sin cambiarlas en nada. Ahí está el acertijo o secreto del cálculo de la atracción apasionada" (Maffesoli, 2008:248). Además extiende pistas para reflexionar sobre la relación estructural entre el aspecto emocional, el sentimiento de pertenencia y un contexto de tensiones y pensar la búsqueda de una vida cotidiana más hedonista en contraposición a una determinada por el "deber ser" y el trabajo.

Vivimos un momento de ebullición, de acontecimientos que demandan un conocimiento plural y desprejuiciado. Atrás quedan las esencialidades, las fijezas y las separaciones taxativas. La vitalidad de los hechos revela que viene emergiendo una nueva forma de agregación social; que tal vez resulte difícil conceptualizarla rápidamente, pero, al menos es posible trazar sus contornos. 


\section{Reflexiones finales}

En este trabajo desarrollamos aspectos teóricos y metodológicos para la interpretación de un fenómeno emergente como la "neorruralidad" en la Argentina. Las reflexiones teóricas expuestas pretendieron ser un aporte a la lectura de un microuniverso sociocultural donde las representaciones y las prácticas de actores nativos e inmigrantes se articulan a través de procesos de comunicación y constituyen la identidad comunitaria.

La población en estudio se presenta así como una metáfora espacio-temporal de la contemporaneidad. Los grupos (diferentes círculos), múltiples y complejos, se encuentran fuertemente unidos por el sentimiento común de quaer al pueblo; situación que va estructurando una memoria colectiva cuya diversidad es fundadora. En líneas generales podemos decir que el sentido de comunidad nace de esta unión del sentir compartido de juicios y prejuicios por el "otro" no-permanente o itinerante en el lugar y el turista. Pero, si las personas no se hablan en las calles, no comparten el espacio de la plaza pública ¿cómo pueden saber quiénes son como grupo? Estructuralmente, es esta diversidad lo que asegura la unicidad del pueblo. Es la tensión entre los diversos grupos lo que afirma la perennidad y renovación del conjunto. En efecto, la acentuación espacial no es un fin en sí mismo, es lo que les devuelve el sentido de la comunidad por permitirles redes de relaciones. "La proxémica remite esencialmente a la fundación de una sucesión de 'nosotros', que constituye la sustancia misma de toda socialidad" (Maffesoli, 2008: 242).

La comunidad constituida por microuniversos simbólicos se hace a partir del sentimiento de pertenencia y en el marco de una red de comunicación. Como lo hicimos notar a lo largo de este texto, encontramos anacrónico seguir pensando lo rural como sinónimo de una cultura ligada al mundo agrario, con una población escasa, homogénea y formas de vida dominadas por lo tradicional, el sentir comunitario y la solidaridad mecánica. No obstante, la noción de configuración cultural permite generar una noción propia de comunidad: el espacio de lo comín, entendido como lo que emerge -y no como lo nuevo- por constituirse de elementos que se ocupan de un devenir, al mismo tiempo que son contradictorios entre sí dentro de una contemporaneidad.

Al partir del supuesto de que el proceso comunicativo es el momento relacionante de la diversidad sociocultural y, por lo tanto, espacio del intercambio, entendemos el sentido de la comunidad desde la construcción que los actores sociales realizan de un epaciodelo comín puddo donde se enlazan sentidos, temporalidades y territorialidades diversas. Este enjambre es lo que emerge como la neorruralidad y, debido a la multidimensionalidad que su significado abraza, debe interpretarse desde un enfoque transdisciplinar antroposoiocomnicadional.

De esta forma, es posible atender a la excepcionalidad de un estilo de vida rural ya no más contrapuesto a la ciudad, sino fusionado y hoy todavía un collagebricdaje donde nadie sabe muy bien quien es; y donde el señor urbano en sus versiones de "hippie" y "gingo" quiere ser "paisamo" y éste último quiere ser urbano. En ambos casos, no desde una ratificación explícita pero sí desde una admiración implícita e irritada. 


\section{Referencias bibliográficas}

Abu-Lughod, L. (2006) [1999]: "Interpretando la(s) cultura(s) después de la televisión: sobre el método", en Iconos. Revista de Ciencias Sociales. (pp. 119-141)Número 24. Quito: Facultad Latinoamericana de Ciencias Sociales-Sede Académica de Ecuador.

Anderson, B. (1993) [1983].Comunidades imaginadas. Reflexiones sobre el origen y la difusión del nacionalismo. M éxico: FCE.

Appadurai, A. (2001): La modernidad desbordada. Buenos Aires: Fondo de Cultura Económica.

Auge, M . (2007): Por una antropología de la movilidad. Barcelona, España: Gedisa.

Bourdieu, P. y Wacquant, L. (1995): Respuestas. Por una antropología reflexiva. México: Grijalbo.

---- (2007): El sentido práctico. Buenos Aires: Siglo Veintiuno.

Castell, M. 2003 [1998]. "El reverdecimiento del yo: el movimiento ecologista”. (pp. 135137), en La era de la información. Economía, sociedad y cultura. El poder de la identidad. Volumen II. Buenos Aires: Siglo XXI.

Cuche, D. (2002) [1966]: La noción de cultura en las ciencias sociales. Buenos Aires: Nueva Visión.

Elias, N. y Scotson, J. (2000): Os estabelecidos e os outsiders. Río de Janeiro. Zahar.

Geertz, C. (1991) [1973]: La interpretación de las culturas. M éxico, D.F: Gedisa M exicana.

Grimson, A. (2010):"Culture and Identity: two different notions", in Social Identities (pp.63-79). Vol. 16, № 1.

---- (2011a) [1999]: Relatos de la diferencia y la igualdad. Los bolivianos en Buenos Aires. Buenos Aires: Eudeba.

---- (2011b): Los Límites de la Cultura. Crítica de las teorías de la identidad. Buenos Aires: Siglo Veintiuno.

-----, Merenson, Silvina y Noel Gabriel (Comp.). (2011): Antropología ahora. Argentina: Siglo Veintiuno.

Gupta, A. y Ferguson, J. (2008) [1992]: “M ás allá de la 'cultura': espacio, identidad y las políticas de la diferencia", en Antípoda. Revista de Antropología y Arqueología. № 7. Julio-Diciembre de 2008. (pp: 233-256). Bogotá, Colombia. Disponible en: http:/ / antipoda.uniandes.edu.co/ view.php/ 119/ index.php?id=119

Hall, E. T. (1989): El lenguaje silencioso. Madrid: Alianza. 
Hall, S. (2002) [1997]: "El trabajo de la representación", in Stuart Hall (Ed.) Representation: Cultural Representations and Signifying Practices (pp. 13-74). London: Sage Publications. Disponible en: http:/ / www.cholonautas.edu.pe/ 2012/ wpcontent/ uploads/2012/ 04/ tallhall.pdf

---- (2003) [1996]: “1. Introducción: ¿quién necesita 'identidad'?", en Hall, Stuart y Du Gay, Paul. (Comp.) Cuestiones de identidad cultural. (13-39) Buenos Aires: Amorrortu.

Hannerz, U. (1996): Conexiones trasnacionales. Madrid: Catedra.

Harvey, D. (1998): La condición de la posmodernidad. Investigación sobre los orígenes del cambio cultural. Buenos Aires: Amorrortu.

Jodelet, D. (1986): "La representación social: Fenómenos, conceptos y teoría", en Serge Moscovici Psicología Social II (pp. 469-494). Barcelona, España: Paidós.

---- (1989): "Représentations sociales: un domaine en expansion", in Denise Jodelet (Org.) Les représentations sociales. París: PUF.

Lefebvre, H. (1991): The Production of Space. Cambridge. Blackwell Publishers.

Maffesoli, M. (2004) [1988]: El tiempo de las tribus. El ocaso del individualismo en las sociedades posmodernas. M éxico: Siglo veintiuno.

Martín-Barbero, J. (1991) [1987]: De los medios a las mediaciones. Comunicación, cultura y hegemonía. M éxico: Gustavo Gili.

Massoni, S. (2013): Metodologías de la comunicación estratégica. Del inventario al encuentro sociocultural. Rosario: Homo Sapiens; Facultad de Ciencia Política - UNR, Argentina y Benemérita Universidad Autónoma de Puebla.

Merenson, S. (2012): "Haciendo una pasada: bordes, jerarquía y legitimación de la desigualdad social en un puerto argentino", en Revista Alteridades 43. Identidades, diferencias y desigualdades (pp.47-61). Universidad Autónoma Metropolitana / Unidad Iztapalapa / División de Ciencias Sociales y Humanidades. Disponible en: http:/ / www.uam-antropologia.net/ pdfs/ ceida/ alte 43 5.pdf

Kornblit, A. L. (2007) [2004]: M etodologías Cualitativas en Ciencias Sociales. Modelos y procedimientos de análisis. 2da Edición. Buenos Aires: Biblos M etodologías.

Ortiz, R. (2005) [1996]: Otro territorio. Ensayos sobre el mundo contemporáneo. Buenos Aires: Universidad Nacional de Quilmes Editorial.

Reguillo Cruz, R. (2005) [1996]: La construcción simbólica de la ciudad: Sociedad, desastre y comunicación. México: Instituto Tecnológico y de Estudios Superiores de Occidente.

Schmucler, H. (1997): Memoria de la Comunicación. Buenos Aires: Biblos. 
Sennett, R. (2002): “Primera parte: Escasez de respeto", en El Respeto. Sobre la dignidad del hombre en un mundo de desigualdad (pp.17-70). Barcelona: Anagrama.

Simmel, G. (1986): El individuo y la libertad. Ensayos de crítica de la cultura. Barcelona, España. Ediciones Península.

Thompson, E. P. (1995): "Introducción: Costumbre y cultura y Patricios y Plebeyos", en Costumbres en común (pp.13-115). Barcelona: Crítica, Grijalbo M ondadori.

Trimano, L. G. (2014): De la ciudad al campo. Tensiones entre culturas emergentes y preexistentes. El caso de Las Calles, Traslasierra, Córdoba. (Tesis doctoral). Escuela de Ciencias de la Información. Facultad de Derecho y Ciencias Sociales. Universidad Nacional de Córdoba, Córdoba, Argentina.

---- (2015): "Integración social y nueva ruralidad: ser ¿"hippie"? en el campo", en Revista de Antropología Social 24, (317-348) Universidad Complutense de Madrid. ISSN 1131-558X. ISSN-e 1988-2831. Disponible en: http://revistas.ucm.es/index.php/RASO/article/view/50660/47056

\section{Notas}

(1) Una trama emergente donde actores diferentes y contiguos interactúan y se ligan, mediante procesos de comunicación, al espesor cultural de una comunidad delineando su sentido (Trimano, 2014).

(2)Trimano, L. (2015). "Integración social y nueva ruralidad: ser ¿"hippie"? en el campo. En Reista deAntropdoǵa Social 24, 317-348 Universidad Complutense de Madrid. Trimano, L. (2014). "De la ciudad al campo. Tensiones entre culturas emergentes y preexistentes. El caso de Las Calles, Traslasierra, Córdoba”. (Tesis dotaral). Escuela de Ciencias de la Información, Facultad de D erecho y Ciencias Sociales, Universidad Nacional de Córdoba, Argentina (Beca Interna de Finalización de D octorado CO NICET). Consdidacón de espacio soial yeconómico dd mecado local en La Granja y reuperación de saberes aulturales y ambientales en las Sieras Chicas (Proyecto con Subsidio de la Secretaría de Extensión Universitaria. UNC. Res. SEU 114/ 14). Reecnstruyendb Idatidades Commicaión Educativa Rural para \& Desamdlo SocioCultural yTeritarial da NorostedeCárdba. (Proyecto Nacional de Voluntariado Universitario. Res. Secretaría de Políticas Universitarias N 1545 del 28/ 09/ 2011. Expediente N² 3504/ 11).Reuperando saberes ambietales y agroedógicos desdela prádica radial en la esauda. Caso Las Calles, Tradasiera, Córdba. (Programa de Becas-Subsidios a Proyectos de Extensión, SEU, UNC, Res. HCS $\mathrm{N}^{\circ}$ 1457/2010). Apartes para la Construción de un Desarrdlo Socicteritarial Agreedógio en Commidades deTraslasiera deCórdba. (Proyecto con Subsidio de la SEU, UNC. Res. SEU No 22/ 10/ 2010).

(3) Se coteja con datos insuficientes, sobre población clasificada por origen, aportados por censos nacionales (1947-2010).

(4) Categoría nativa para referirse a sujetos inmigrantes de capital económico, cultural y simbólico.

(5) Epíteto despectivo utilizado por los nativos para referirse a jóvenes inmigrantes con hábitos de vida alternativos a las costumbres arraigadas en la idiosincrasia del lugar. Un análisis extendido de esta experiencia migratoria puede encontrase en Trimano (2015).

(6) Expresión autorreferencial de personas "madiasyciadas" en LasCalles

(7) Clasificación nativa para autodenominarse auténtico habitante de LasCalles

(8) Taxonomía utilizada por inmigrantes para nombrarse; por nativos para designar a seres desprovistos de auténtica residencia. 
(9) La palabra cultura es utilizada con fines descriptivos; cuestionamos dicho término "debido a su tendencia a empujarnos hacia ideas demasiado consensuales y holísticas" (Thompson, 1995: 26) y a descuidar las heterogeneidades que se dan en su interior.

(10) A partir de normas de la escritura etnográfica se utiliza como criterio tipográfico "itálica entre comillada" para las citas textuales de informantes en el interior del texto que sean inferiores a tres líneas.

(11) La elección de mayores de 20 años se fundamenta en que suponemos que a esa edad comienza a manifestarse una identidad colectiva y se han superado los procesos de conflictividad del período adolescente, en donde esta configuración "choca" con el proceso de conformación de la identidad personal. No se incluye en el análisis la población turística por no residir en la localidad.

(12) En la investigación realizada previamente detectamos expresiones nativas para tipificar a personas foráneas. Estas categorías son clave de lectura por corresponderse con proyectos residenciales ocultos detrás de la eiquata. 


\section{(c) (i) (2) \\ Licencia Creative Commons \\ Miguel Hernández Communication Journal \\ mhcj.es}

\section{Forma de citar este artículo en las bibliografías}

Dra. Luciana Geraldine Trimano (2015): "La Neorruralidad desde un Enfoque Antroposociocomunicacional”, en Miguel Hernández Communication Journal, nº6, páginas 195 a 217. Universidad Miguel Hernández, UMH (Elche-Alicante). Recuperado el _- de de 20 de: [link del artículo en mhjournal.org] 